\title{
Risk factors among elderly for short term deaths related to high levels of air pollution
}

\author{
L Filleul, I Baldi, J-F Dartigues, J-F Tessier
}

Occup Environ Med 2003;60:684-688

See end of article for authors' affiliations

\section{Correspondence to:} Dr L Filleul, Laboratoire Santé Travail

Environnement, Université de Bordeaux 2, 146 rue Léo Saignat, 33076 Bordeaux, France;

laurent.filleul@ isped.u-bordeaux $2 . \mathrm{fr}$

Accepted 7

November2002
Background: Air pollution has been linked to increased rates of mortality, but little is known about individual characteristics related to the increase in risk.

Aims: To examine short term effects of air pollution on daily mortality in elderly people in Bordeaux and compare characteristics of subjects $\geqslant 65$ years old who died with levels of particulate air pollution. Methods: Daily mortality data from Bordeaux were used to determine the core model of mortality for the period 1988-97. The air pollution indicator was regressed on the core model of mortality, allowing control of the main effect modifiers and confounding factors of air pollution on the same day. The residual series of this regression model was classified from the lowest to the highest to determine "low level days" and "high level days". A sample of 1469 elderly people in a French cohort study were studied.

Results: From 1988 to 1997, 543 subjects died; 55 deaths were during days with low air pollution and 51 during days with high air pollution. Only gender differed significantly according to both types of days, with a proportion of women significantly higher in high air pollution days than men. After adjustment for smoking habits, the odds ratio was 5.2 for women.

Conclusion: The risk of mortality between women and men was determined on days with "high air pollution levels" above the 50-90th centiles compared to below the 10th centile. No clear pattern was observed between days with low levels of air pollution and the different centiles of exposure.
$\mathrm{N}$ umerous time series studies around the world have reported increases in the daily incidence of nonaccidental mortality associated with increases in daily levels of particulate air pollution. ${ }^{1-4}$ Various measurements of particulate pollution were used in the different studies; changes in daily mortality associated with particulate air pollution ranged from about $0.5 \%$ to $1.5 \%$ per $10 \mu \mathrm{g} / \mathrm{m}^{3}$ increase in PMl0 concentrations, or about 5 or $6 \mu \mathrm{g} / \mathrm{m}^{3}$ in $\mathrm{PM}_{2.5}$ concentrations. ${ }^{5}$ Results have been discussed because various lag relations between air pollution and deaths were used. Furthermore, increases in risk were observed in specific subgroups: children ${ }^{6-8}$ and the elderly. ${ }^{9-12}$ If associations are well documented, little is known about the characteristics of persons that would explain the increased risk of adverse events related to air pollution. The health effects on mortality associated with short term increases in particulate air pollution are relatively minor, but identification of susceptible subgroups is important for public health purposes. In Philadelphia, Pennsylvania, Schwartz and Dockery reported that people older than 65 years of age had a somewhat increased risk of death for the years 1973 to $1980 .{ }^{13}$ Gouveia and Fletcher confirmed these results in São Paulo, the most urbanised, industrialised, and affluent city in Brazil with a population of about 9.5 million inhabitants. The authors

\section{Main messages}

- Air pollution is associated with mortality in the elderly in Bordeaux, France.

- Days were defined according to their pollution levels.

- Risk factors among the elderly were compared for deaths related to high levels of air pollution.

- Effects of air pollution were greater for women than for men among the elderly.

- No clear gradient of effect was observed for air pollution exposure. showed a significant 3-4\% increase in the number of daily deaths for all causes in the elderly compared to a nonsignificant ( $1 \%$ ) increase in the all ages population. ${ }^{14}$ It seems evident that the elderly are more susceptible, but some authors think this answer is too simplistic and argue that individual factors (risk factors, chronic disease) may play a greater role in the frailty of subjects than simply age. ${ }^{5}$

The purpose of this article is to examine short term effects of air pollution on daily mortality in elderly people in Bordeaux (France), and then to survey specific characteristics of subjects aged 65 years and older who died on days with high levels of particulate air pollution, with individual data from a cohort of the elderly.

\section{MATERIALS AND METHODS \\ Ecological analysis}

We used a retrospective ecological study of the population of the city of Bordeaux located in southwestern France.

Study area and environmental data

The agglomeration of Bordeaux is extended over a surface of $560 \mathrm{~km}^{2}$ and contained approximately 558000 habitants and 83100 people aged $\geqslant 65$ years according to the 1990 census. Sources of urban air pollution are mainly motor vehicle emissions. Air pollution data were obtained from the APPA (Association de Prévention de la Pollution Atmophérique),

\section{Policy implications}

- Air pollution is a public heath problem among the elderly in developed countries.

- Preventive actions must be performed, even on days with low levels of air pollution.

- Major efforts for medical follow up must be done among the elderly, particularly women. 
which operated a local monitoring network from 1981 to 1997. Four stations were chosen to represent background inner city air quality levels (that is, stations not directly influenced by industrial or road traffic sources of pollution). The ambient urban stations must have been sufficiently correlated (that is, correlation $>0.70$ ) and must have sufficiently similar mean levels of pollution. We constructed exposure indicators by calculating the arithmetic mean of daily concentrations recorded by the ambient urban stations selected. Stations located in limited access highways were excluded. Black smoke (BS) measured by reflectometry was the only air pollution available indicator for the period 1981-97. Meteorological data (daily temperature and daily relative humidity) were provided by Météo-France.

\section{Health data}

Mortality data during the 1988-97 period were provided by the National Institute of Health Medical Research, which carries out the coding of the medical causes of death according to the International Classification of Diseases, 9th revision (ICD-9) We considered all deaths except those from accidental causes (ICD-9 <800) recorded according to the area of residence of the deceased. During the period between 1988 and 1997, 44561 deaths were recorded in the Bordeaux area, and 36246 for those 65 years of age and older.

Influenza data were provided by the Teleprocessing National Network of monitoring and information on transmissible diseases during the period 1988-97. This network was developed since 1984, and based on sentinel general practitioners to provide a global information system in public health, with the triple aim of collecting, analysing, and redistributing all relevant information in the field of communicable diseases. ${ }^{15}$

\section{Statistical analysis}

We used daily mortality data from Bordeaux to determine the core model of mortality. We analysed the data with a generalised additive robust Poisson regression model ${ }^{16}$ In this model the outcome is assumed to depend on a sum of nonparametric smooth functions for each variable that models the potential non-linear dependence of daily mortality on weather and season. The model is of the form:

$$
\log \left[E\left(Y_{t}\right)\right]=\beta_{0}+\beta_{1} f_{1}\left(x_{1}\right)+\ldots+\beta_{p} f_{p}\left(x_{p}\right)
$$

Where $E\left(Y_{t}\right)$ is the expected value of the daily count of deaths $Y_{t}$ and $f_{p}$ are the smooth functions of the covariates $x_{p}$. For the $f_{i}$ we used a moving regression smoother, loess. The final model resulted in a Poisson regression model in which nonparametric smoothing functions were used and overdispersion control was used. It included loess function, with a reasonable degree of smoothing (span) that was based on graphical output for the following: time to control temporal trends and seasonal variations; influenza covariates to control the influence of influenza epidemics; and temperature and relative humidity to control their short term effect on mortality. Binary variables for day of the week and holidays were also introduced. For each covariate, various lags were evaluated. To examine the effect of smoothing temporal variations on the estimates of air pollutant effects, we tested different degree of smoothing (span). The preferred span provided a small Akaike information criterion (AIC).

\section{Individual analysis}

To identify risk factors of death days with high levels of air pollution, we used the core model of mortality obtained in Bordeaux and data of the PAQUID cohort.

\section{PAQUID cohort population}

The PAQUID cohort which aims to study cerebral and functional factors of aging was designed to prospectively study a representative random sample of 3777 people aged 65 years and older at baseline and living at home in the administrative areas of Gironde and Dordogne in southwestern France. Subjects were selected from the general electoral lists of the Gironde and Dordogne areas after stratification for age, sex, and urban unit. Trained psychologists interviewed subjects at home at baseline in 1988. Interviews made it possible to fill in a detailed questionnaire on sociodemographic characteristics and health status. More information on the general methodology and major results of PAQUID have been published elsewhere. ${ }^{17}{ }^{18}$ In our study, we selected only subjects of the PAQUID cohort living in Bordeaux because data on air pollution were only available for this area. There were 1469 subjects in our sample; 543 deaths were recorded during the period 1988-97.

\section{Statistical analysis}

The air pollution indicator is regressed on the core model of mortality, allowing for control of the main effect modifiers and confounding factors of air pollution on the same day. ${ }^{19}$ The residual series of this regression model are classified from the lowest to the highest with the corresponding days; the 10th and the 90th centiles of the days were chosen as thresholds for determining respectively "low level days" and "high level days". We then compared characteristics of the elderly from the PAQUID cohort who died between 1988 and 1997, the 10th and the 90th centiles of the days.

The association between individual factors was calculated by odds ratio using logistic regression, taking into account the main characteristics related to the death (gender, sex, educational level, occupational, smoking habits, etc). We considered the risk of mortality between women and men for different definition of days with "high air pollution levels" above the 50th to 90th centiles compared to below the 10th centile.

\section{RESULTS}

\section{Ecological analysis}

Table 1 presents mortality and environmental indicators. The daily mean number of deaths were approximately 10 for total mortality (maximum 24). Figure 1 shows the non-parametric

Table 1 Summary of the daily figures for the number of deaths for elderly, the concentrations of air pollutants, and meteorological variables; Bordeaux, France (1988-97)

\begin{tabular}{lccrrrrr}
\hline & Days & Minimum & $\begin{array}{l}\text { 25th } \\
\text { centile }\end{array}$ & Mean & Median & $\begin{array}{l}\text { 75th } \\
\text { centile }\end{array}$ & Maximum \\
\hline Mortality counts & 3653 & 1.00 & 8.00 & 9.90 & 10.00 & 12.00 & 24.00 \\
& & & & & & & \\
Black smoke, $24 \mathrm{~h}\left(\mathrm{\mu g} / \mathrm{m}^{3}\right)$ & 3653 & 1.75 & 10.10 & 16.96 & 14.48 & 20.55 & 98.97 \\
Minimal temperature $\left({ }^{\circ} \mathrm{C}\right)$ & 3653 & -9.40 & 5.30 & 9.29 & 9.60 & 13.60 & 23.40 \\
Maximal temperature & 3653 & -2.70 & 13.50 & 18.76 & 18.20 & 24.20 & 38.80 \\
Relative humidity $(\%)$ & 3653 & 13.00 & 46.00 & 59.88 & 60.00 & 74.00 & 100.00 \\
\hline
\end{tabular}




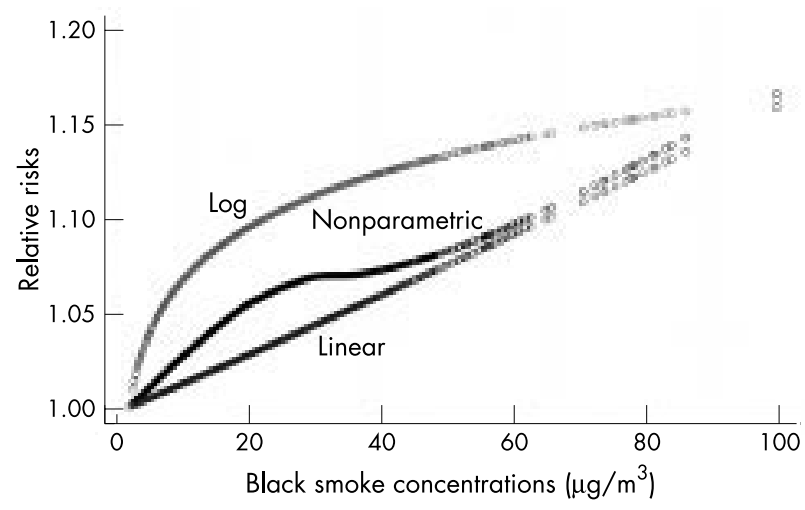

Figure 1 Smooth plot of relative risk of all non-accidental mortality in elderly related to black smoke (lag 0) in Bordeaux, France. The models contains an intercept term, loess smoother for temporal variations, for influenza and relative humidity, indicators for day of the week, and holidays.
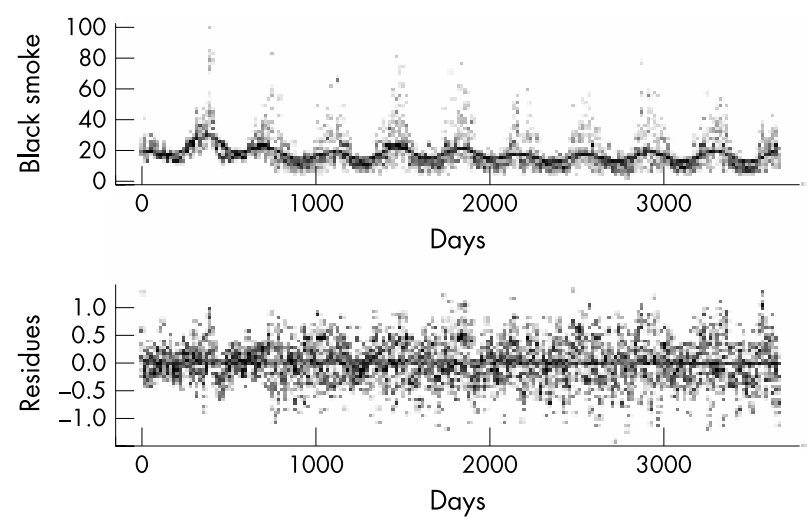

Figure 2 Black smoke concentration in $\mu \mathrm{g} / \mathrm{m}^{3}$ and residues after adjusting for seasonal trend, influenza epidemics, temperature, and humidity in Bordeaux (1988-97).

and parametric smooth plots (linear and log) of relative risk for all non-accidental causes after controlling for covariates. There is no indication that a threshold in the relation between BS and all non-accidental mortality exists; the shape of this relation is approximately linear. On the basis of the same graphical dose-response relation plot, we found that a 10 $\mu \mathrm{g} / \mathrm{m}^{3}$ increased in BS was associated with a $1.5 \%$ (95\% CI $0.3-2.8 \%)$ increase in all non-accidental mortality for elderly persons on the same day.

\section{Individual analysis}

We used the core model with pollution levels on the same days to define days with high levels of air pollution. Figure 2 presents the initial time series of black smoke levels and the residual series (after adjusting for influenza epidemics, temperature, relative humidity, and temporal variations). Controlling for potential confounding factors, the 10th and the 90th centiles of the residual series were chosen as thresholds for determining respectively "low level days" and "high level days" (fig 3). Mean BS levels were $7.4 \mu \mathrm{g} / \mathrm{m}^{3}$ on days with low pollution and $30.1 \mu \mathrm{g} / \mathrm{m}^{3}$ on days with high pollution.

Of the 1469 subjects of the PAQUID cohort living in the Bordeaux area, 543 died between 1988 and 1997. We identified 55 deaths during days with low air pollution and 51 deaths during days with high air pollution. The difference was not significant $(\mathrm{p}=0.67)$.

Table 2 presents the characteristics of subjects. No differences were found for educational level, marital status, occupation, smoking habits, and pre-existing disease. Only gender differed significantly between both types of days. The

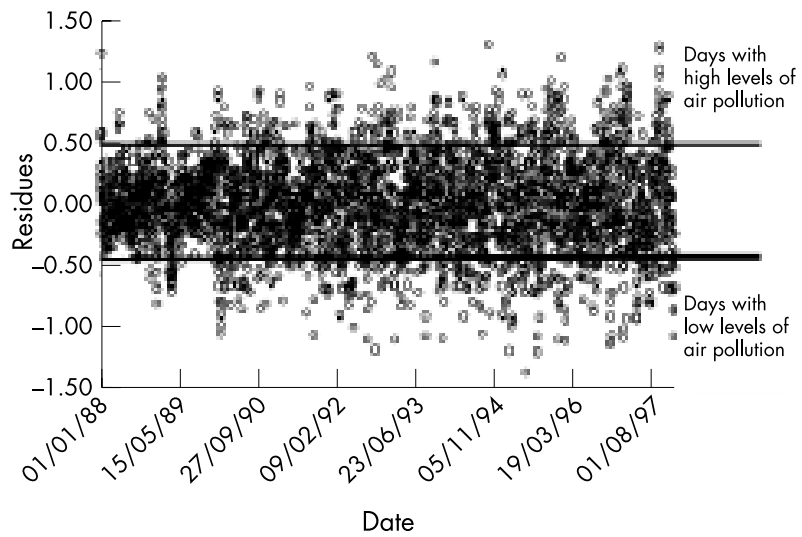

Figure 3 Residues of black smoke after adjusting for seasonal trend, influenza epidemics, temperature, and humidity versus time. Lines show the $10 \%$ of days with high air pollution and the $10 \%$ of days with low air pollution.

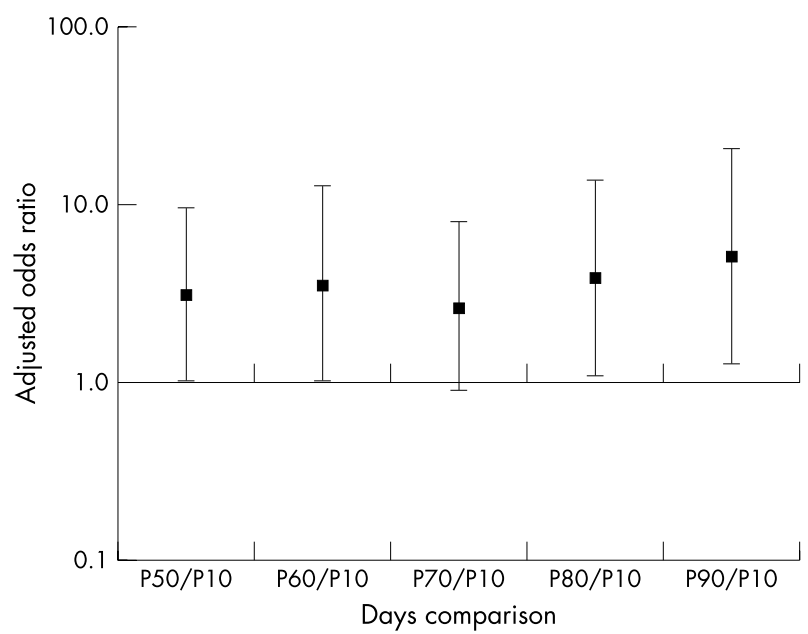

Figure 4 Adjusted mortality for women compared to men according to centiles of air pollution levels (adjusted for smoking habits).

proportion of women was significantly higher on high air pollution days than men. After adjustment for smoking habits, elderly women had a greater risk of dying on high pollution days compared to men (OR 5.2, 95\% CI 1.32 to 20.65). To investigate a gradient of effect across the exposure, fig 4 presents risks to death for women compared to men according to centiles of air pollution levels. No clear patterns were observed between days with low levels of air pollution and the different centiles of exposure.

\section{DISCUSSION}

We found a significant association between daily mortality and black smoke among the elderly in Bordeaux. Furthermore, our data suggest that the risk of death on days with high level of air pollution is larger for elderly women than elderly men. This risk of death concerns only deaths in "acute situations"; also we do not have study the lag between exposure and death. There is accumulating evidence that ambient particulate air pollution is associated with daily non-accidental deaths whatever the population, but we ignore factors possibly conferring susceptibility to the acute role of air pollution. In 1994, Schwartz examined the age of death on death certificates on the days with the highest and lowest $5 \%$ of particulate air pollution in Philadelphia during the years 1973-80 
Table 2 Characteristics of subjects of the PAQUID cohort deaths on days with low and high air pollution in Bordeaux

\begin{tabular}{|c|c|c|c|}
\hline & $\begin{array}{l}\text { Deaths on low air } \\
\text { pollution days } \\
n=55(100 \%)\end{array}$ & $\begin{array}{l}\text { Deaths on high air } \\
\text { pollution days } \\
\mathrm{n}=51(100 \%)\end{array}$ & $\mathrm{p}$ value \\
\hline Age of death (mean, years) & 84.0 & 84.8 & 0.59 \\
\hline \multicolumn{4}{|l|}{ Age of death group } \\
\hline $65-74$ years & $6(10.9)$ & $5(9.8)$ & \multirow{3}{*}{0.34} \\
\hline $75-84$ years & $22(40.0)$ & $14(27.5)$ & \\
\hline$\geqslant 85$ years & $27(49.1)$ & $32(62.7)$ & \\
\hline \multicolumn{4}{|l|}{ Gender } \\
\hline Men & $36(65.5)$ & $23(45.1)$ & \multirow[t]{2}{*}{0.04} \\
\hline Women & $19(34.5)$ & $28(54.9)$ & \\
\hline \multicolumn{4}{|l|}{ Marital status } \\
\hline Married/co-habitation & $31(56.3)$ & $25(49.0)$ & \multirow{3}{*}{0.64} \\
\hline Widowed & $20(36.4)$ & $20(39.2)$ & \\
\hline Single/divorced/separated & $4(7.3)$ & $6(11.8)$ & \\
\hline \multicolumn{4}{|l|}{ Educational level } \\
\hline No school/primary without diploma & $13(23.6)$ & $17(33.3)$ & \multirow[t]{2}{*}{0.27} \\
\hline Primary with diploma & $42(76.4)$ & $34(66.7)$ & \\
\hline \multicolumn{4}{|l|}{ Occupational } \\
\hline Domestic employees, women at home & $5(9.1)$ & $14(27.5)$ & \multirow{5}{*}{0.10} \\
\hline Blue collar workers & $20(36.3)$ & $12(23.5)$ & \\
\hline Craftsmen, shopkeepers & $6(10.9)$ & $8(15.7)$ & \\
\hline Other employees & $15(27.3)$ & $10(19.6)$ & \\
\hline Intellectual occupation & $9(16.4)$ & $7(13.7)$ & \\
\hline \multicolumn{4}{|l|}{ Smoking habits } \\
\hline No smoker & $10(18.2)$ & $3(5.9)$ & \multirow[t]{3}{*}{0.15} \\
\hline Former smoker & $19(34.6)$ & $25(41.2)$ & \\
\hline Current smoker & $26(47.2)$ & 27 (52.9) & \\
\hline BMI $\left(\mathrm{kg} / \mathrm{m}^{2}\right)$ & 24.0 & 22.4 & 0.46 \\
\hline \multicolumn{4}{|l|}{ Asthma } \\
\hline Yes & $2(3.6)$ & $1(2.0)$ & \multirow[t]{2}{*}{ - } \\
\hline No & $53(96.4)$ & $50(98.0)$ & \\
\hline \multicolumn{4}{|l|}{ Heart failure } \\
\hline Yes & $2(3.6)$ & $4(7.8)$ & \multirow[t]{2}{*}{0.35} \\
\hline No & $53(96.4)$ & $47(92.2)$ & \\
\hline \multicolumn{4}{|l|}{ Dyspnoea } \\
\hline Yes & $27(49.1)$ & 25 (49.0) & \multirow[t]{2}{*}{0.99} \\
\hline No & $28(50.9)$ & $26(51.0)$ & \\
\hline \multicolumn{4}{|l|}{ Depressive symptoms } \\
\hline Yes & $16(29.1)$ & $16(31.4)$ & \multirow[t]{2}{*}{0.80} \\
\hline No & 39 (70.9) & 35 (68.6) & \\
\hline \multicolumn{4}{|l|}{ Death in a medical unit* } \\
\hline Yes & $30(71.4)$ & $29(72.5)$ & \multirow[t]{2}{*}{0.91} \\
\hline No & $12(28.6)$ & $11(27.5)$ & \\
\hline \multicolumn{4}{|l|}{ Cause of death } \\
\hline Cardiovascular & $23(41.8)$ & $23(45.10)$ & 0.73 \\
\hline Respiratory & $5(9.1)$ & $4(7.8)$ & 0.82 \\
\hline
\end{tabular}

and showed an increased risk of death during the high pollution days. ${ }^{19}$ The increased risk of death was greater in the elderly.

It seems plausible that the elderly are most likely to be susceptible; a recent time series study by Gouveia et al found a significant trend of increasing risk of death according to age, with effects most evident for subjects 65 years and over. ${ }^{14}$ Considering individual factors, Zanobetti and Schwartz, in a time series study, found that the association between mortality and $\mathrm{PM}_{10}$ was higher in women than in men, but they observed only weak evidence of the effect modification due to social factors, race, and gender. ${ }^{20}$ Zanobetti and Schwartz thought that the association between particles and mortality could depend more on existing medical conditions than on social factors. A study suggests that patients with acute respiratory infections or defects in electrical control of the heart are a risk group for particulate matter effects, but this effect did not vary by age and race. ${ }^{21}$ However, Sunyer et al showed a higher effect of particulate air pollution on the risk of mortality for women than for men in patients with chronic obstructive pulmonary disease. ${ }^{22}$ The reasons for the differences by sex are unclear. Some investigations found a greater deposition of particles in the lungs of women. ${ }^{20}$ However, Bennett et al suggested that a difference in total deposition in the elderly between males and females may be indicated by a greater ventilation in males. ${ }^{23}$ Other studies have shown that the effects of smoking on lung function may be greater in women than in men. ${ }^{24}$ However, we found a greater risk for women after adjustment for smoking habits. Furthermore, this greater risk was constant and no gradient of exposure was observed. This results confirm that there was no threshold, and whatever the air pollution level, there is always a part of population which is more sensitive. ${ }^{25}$

According to educational level or occupation, we observed a slight but non-significant tendency. Zanobetti and Schwartz found that persons with less than a high school education had a higher particles induced mortality than persons with at least college education, but the difference was not significant. ${ }^{20}$ However, results of Zanobetti and Schwartz came from a study based on aggregated data, which cannot determine individual sensibility. A reanalysis of individual data of two American cohorts (the six cities study ${ }^{26}$ and the American Cancer Society study $^{27}$ ) explored the existence of sensitive subgroups, ${ }^{28}$ and found the relative risk of mortality associated with fine particles to be greater among individuals with high school education or less, compared to those with more than high school education. The analysis concerned long term effects, but provides evidence that pre-existing diseases are not the only explanation for susceptibility to air pollution. 
In our study, the number of deaths is low, but as far as we know, this paper is the first attempt to investigate sociodemographic and individual factors of the elderly dying on days with high levels of particulate air pollution. We confirm that data from cohorts which were established decades ago may be efficiently used to assess health effects and to identify the most susceptible subgroups in the population..$^{29}$ Our findings suggest that women among the elderly are a susceptible population to particulate air pollution. Nevertheless, further epidemiological studies are required to confirm these findings.

\section{ACKNOWLEDGEMENTS}

This work was supported by the ADEME (French Environment and Energy Agency). The authors thank S Médina, A le Tertre, and P Quénel for their helpful comments on the method, and S Larrieu for her help with data collection.

\section{Authors' affiliations}

L Filleul, I Baldi, J-F Tessier, Laboratoire Santé Travail Environnement, Bordeaux, France

J-F Dartigues, INSERM U330, Bordeaux, France

\section{REFERENCES}

1 Samet JM, Dominici F, Curriero FC, et al. Fine particulate air pollution and mortality in 20 US Cities, 1987-1994. N Engl J Med 2000:343:1742-9.

2 Katsouyanni K, Touloumi G, Spix C, et al. Short term effects of ambient sulfur dioxide and particulate matter on mortality in 12 European cities: results from time series data from the APHEA project. BM 1997; 314:1658-63

3 Lee JT, Kim H, Hong YC, et al. Air pollution and daily mortality in seven major cities of Korea, 1991-1997. Environ Res 2000;84:247-54.

4 Simpson RW, Williams G, Petroeschevsky A, et al. Associations between outdoor air pollution and daily mortality in Brisbane, Australia. Arch Environ Health 1997:52:442-54.

5 Pope CA. Epidemiology of fine particulate air pollution and human health: biologic mechanisms and who's at risk? Environ Health Perspect 2000;108:713-23

6 Pereira LAA, Loomis D, Conceicao GMS, et al. Association between air pollution and intrauterine mortality in Sao Paulo, Brazil. Environ Health Perspect 1998:106:325-9.

7 Ostro BD, Eskeland GS, Sanchez JM, et al. Air pollution and health effects: a study of medical visits among children in Santiago, Chile. Environ Health Perspect 1999; 107:69-73.

8 Conceicao GMS, Miraglia SGEK, Kishi HS, et al. Air pollution and child mortality: a time-series study in Sao Paulo, Brazil. Environ Health Perspect $2001 ; 109: 347-50$

9 Schwartz J, Spix C, Touloumi G, et al. Methodological issues in studies of air pollution and daily counts of deaths or hospital admissions. J Epidemiol Community Health 1996:50:S3-11.
10 Boria-Aburto VH, Castillejos M, Gold DR, et al. Mortality and ambient fine particles in southwest Mexico City, 1993-1995. Environ Health Perspect 1998; 106:849-54

11 Schwartz J. The distributed lag between air pollution and daily deaths. Epidemiology 2000;11:320-6.

12 Katsouyanni K, Touloumi G, Samoli E, et al. Confounding and effect modification in the short-ferm effects of ambient particles on total mortality: Results from 29 European cities within the APHEA2 project. Epidemiology 2001;12:521-31.

13 Schwartz J, Dockery DW. Increased mortality in Philadelphia associated with daily air pollution concentrations. Am Rev Respir Dis 1992;145:600-4.

14 Gouveia N, Fletcher T. Time series analysis of air pollution and mortality: effects by cause, age and socioeconomic status. J Epidemiol Community Health 2000;54:750-5.

15 Valleron AJ, Garnerin P. Computer networking as a tool for public health surveillance: the French experiment. MMWR 1992;41:101-10.

16 Hastie T, Tibshirani R. Generalized additive models-some applications. J Am Stat Assoc 1987;82:371-86.

17 Dartigues JF, Gagnon M, Michel P, et al. The Paquid research program on the epidemiology of dementia. Methods and initial results. Rev Neurol $1991 ; 147: 225-30$

18 Barberger-Gateau P, Chaslerie A, Dartigues JF, et al. Health measures correlates in a French elderly community population: the PAQUID study. J Gerontol 1992;47:S88-95.

19 Schwartz J. What are people dying of on air pollution? Environ Res 1994:64:26-35

20 Zanobetti A, Schwartz J. Race, gender and social status as modifiers of the effects of PM10 on mortality. J Occup Environ Med 2000;42:469-74

21 Zanobetti A, Schwartz J, Gold D. Are there sensitive subgroups for the effects of airborne particles? Environ Health Perspect 2000;108:841-5.

22 Sunyer J, Schwartz J, Tobias A, et al. Patients with chronic obstructive pulmonary disease are at increased risk of death associated with urban particle air pollution: a case-crossover analysis. Am J Epidemiol 2000; 151:50-6.

23 Bennett WD, Zeman KL, Kim C. Variability of fine particle deposition in healthy adults: effect of age and gender. Am J Respir Crit Care Med 1996;153:1641-7.

24 Prescott E, Bjerg AM, Andersen PK, et al. Gender difference in smoking effects on lung function and risk of hospitalisation for COPD: results from a danish longitudinal population study. Eur Respir J 1998;10:822-7.

25 Daniels MJ, Dominici F, Samet JM, et al. Estimating particulate matter-mortality dose-response curves and threshold levels: an analysis of daily time-series for the 20 largest US cities. Am J Epidemio 2000; 152:397-406.

26 Dockery DW, Pope III CA, Xu X, et al. An association between air pollution and mortality in six US cities. N Engl J Med 1993;329: 1753-9.

27 Pope CA, Thun M, Namboodiri MM, et al. Particulate air pollution as a predictor of mortality in a prospective study of US adults. Am J Respir Crit Care Med 1995; 151:669-79.

28 Krewski D, Burnett RT, Goldberg MS, et al. Reanalysis of the Harvard Six Cities Study and the American Cancer Society Study of Particulate Air Pollution and Mortality. Cambridge: Health Effects Institute, 2000:246.

29 Kunzli N, Tager IB. Long-term health effects of particulate and other ambient air pollution: research can progress faster if we want it to. Environ Health Perspect 2000;108:915-18. 